\title{
COMPARATIVE STRUCTURAL ANALYSIS OF ANTERIOR AND POSTERIOR WINGS OF THE DRAGONFLY
}

\author{
U.T. BEZERRA ${ }^{1} \&$ N.P. BARBOSA ${ }^{2}$ \\ ${ }^{1}$ Prof. Dr. of Federal Institute of Paraíba, IFPB, João Pessoa-PB, Brasil. \\ ${ }^{2}$ Prof. Dr. of Federal University of Paraíba, UFPB, João Pessoa-PB, Brasil.
}

\begin{abstract}
Dragonflies are insects fitted with two pairs of wings: a narrower pair located on the front side and a wider pair located behind. The geometry of these wings has been studied by other authors, but differences between these are visible, showing structural differences designed by nature. The aim of this paper was to compare the structural behaviour (stress and strain) of both pairs of dragonfly wings. The wings were simulated as grids supported in the animal body, according to natural geometry. The results show that the wings are composed of elements from 3 to 7 faces, and although similar to each other, there are some differences in structure and geometry between them: (i) the posterior wings support greater load because they have larger area (x2.4); (ii) the number of main structures connecting with the body in both is eight; (iii) the main connections in the anterior wings are closer, favouring the direction of flight; (iv) the posterior wings are set closer to the center of gravity of the insect, which causes the body weight to be supported by these wings, the anterior wings getting to the manoeuvres of flight; (v) analysis shows that the anterior wings support more concentrated efforts, while the posterior wings, due to their larger area, have reduced stress; (vi) the same is said of deformations, where the anterior wings deform more than the posterior wings (x2.4). Nature designed dragonfly wings with different geometry and function, in which the anterior wings are responsible for handling the flight, and the posterior wings are responsible for sustaining the animal's body. The ratio between the number of frames and the number of joints is equal to the number of gold (1.618).
\end{abstract}

Keywords: dragonfly, grid, rigid method, wing.

\section{INTRODUCTION}

Natural structures will always be an inspiration to humans. They can either be the structure of a robust tree trunk, or the delicate structure of an amoeba, the underlying idea in each structure will always inspire the human creativity $[1,2,3]$.

Dragonflies, theme of this pleasant Conference, fascinate by their colours, speed, flexibility and lightness. They are part of a group of animals (Fig. 1), with nearly 5,000 species and subspecies belonging to the arthropod phylum, class insecta, order odonata, and two suborders: Anisoptera and zigoptera. [4].

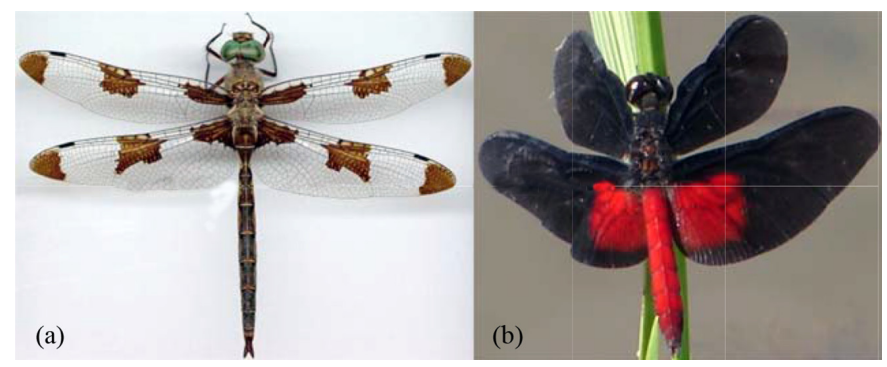

Figure 1: Dragonfly: (a) anisoptera, (b) zigoptera.

(C) 2014 WIT Press, www.witpress.com

ISSN: 1755-7437 (paper format), ISSN: 1755-7445 (online), http://journals.witpress.com

DOI: 10.2495/DNE-V9-N3-190-196 
There are some differences between the suborders, and the greatest interest; here, refers to the dimensions and geometry of their wings. The anisoptera, Fig. (a), have wings of the same order of magnitude, and zigoptera, Fig. (b), have different wings.

Thus, this paper deals with the comparative structural analysis of anterior and posterior wings of a dragonfly, suborder anisoptera. The analysis was performed by employing the Stiffness Method, using the Structural Analysis Program (SAP90) [5]. The wings were considered as grids embedded in the trunk of the animal. We sought to compare mainly the efforts and deformations of joints and frames.

\section{MATERIALS AND METHODS}

A dragonfly was employed to obtain the design of a structure (Fig. 2). The drawing lines represent the frames, and the intersections represent the structural joints (observe the defect highlighted on posterior wing: Fig. 2, yellow circle; may be this is not exactly a defect, but a human limitation in understanding nature!).

The dragonfly wing consists of an exoskeleton connected by membranes, which makes it look like a ribbed slab. Here, the wing was calculated as a grid through the Stiffness Method under static loads. In a second moment, the analysis calculates the wing as a ribbed slab using the Finite Element Method and dynamic loading conditions.

Figure 3 below shows the numbering of the joints and frames of the posterior wing. In this figure, it is possible to understand the difficulty of enumerating the large number of these elements.

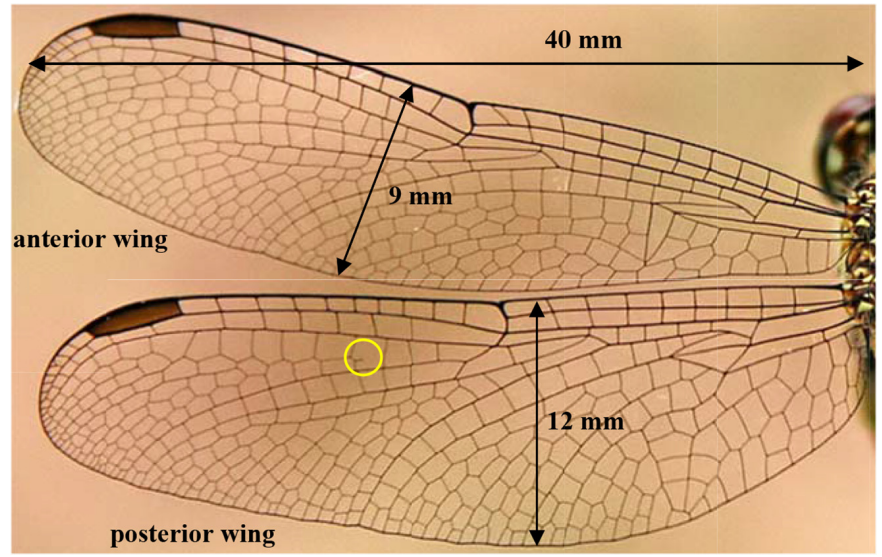

Figure 2: Photo of specimen.

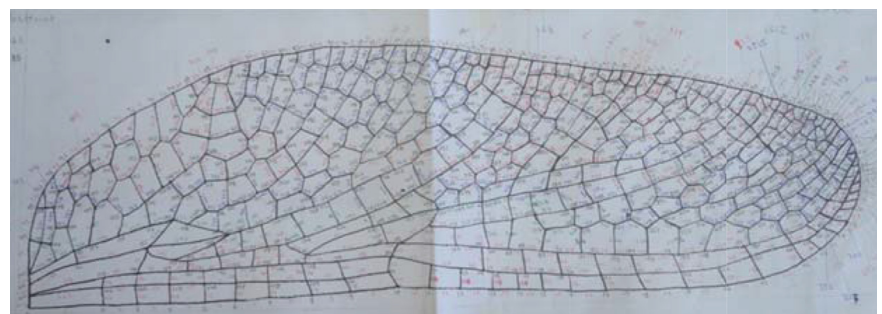

Figure 3: Numbering of joints and frames of the posterior wing. 
The quantities of joints, frames and arrays equations of each wing are seen in Table 1 below.

An interesting observation: the ratio between the number of frames and the number of joints is very close to the known gold number (1.618), which is a very common constant detected in nature (e.g. Fibonacci series, tree leaves, reproduction of rabbits, etc. [6]). In fact, some small frames were not considered in the calculation, which would increase the value of the relation obtained, tending to the golden number.

Two static loading conditions were considered: a loading perpendicular to the plane of the wings (suction and/or pressure of the wind); and loading parallel to the plane, acting on the posterior side of the wing (effect of wind). The value of the load was considered equivalent to a wind of $30 \mathrm{~m} / \mathrm{s}$ $(108 \mathrm{~km} / \mathrm{h} ; 562.5 \mathrm{~Pa})$, which is the maximum wind observed in northeastern Brazil. Due to the second loading condition, that generated a very little result, only the first loading was considered.

Furthermore, due to the reduced dimensions of the loads and dimensions, it was necessary to adopt the following units: (i) force: gram-force $\left(1 \mathrm{gf}=9.82^{-2} \mathrm{~N}\right)$ and (ii) length: millimeter $(\mathrm{mm})$. Other units have been tried, but only they were able to generate significant results.

\section{RESULTS AND DISCUSSION}

Although they are of the same order of magnitude, the wings are purposely (!) a bit different. The anterior wing is longer, narrower, has a smaller area, and presents an angle of attack in its middle part. However, the posterior wing is shorter, wider, strong, and has a larger area (25\%).

The robustness of the posterior wing can be observed through the presence of four hierarchical structures, similar to the fingers of a bat. Similarly, the anterior wing has only three of these structures (Fig. 4).

Table 1: Data of wings.

\begin{tabular}{lcccc}
\hline Wing & Frame & Joint & Equation & Relation F/J \\
\hline anterior & 865 & 537 & 3198 & 1.611 \\
posterior & 998 & 621 & 3714 & 1.607 \\
\hline
\end{tabular}

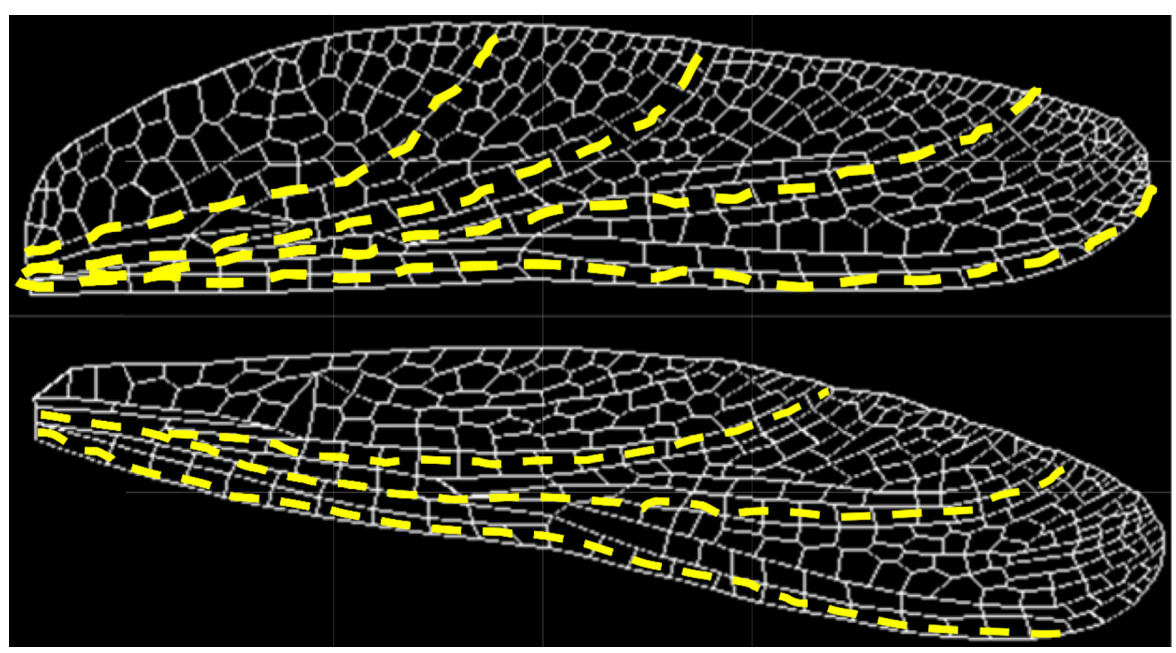

Figure 4: Posterior and anterior wing structures. 
The structural analysis generated the following results: (i) deformation in the $\mathrm{Z}$ axis direction (parallel to the direction of gravity); (ii) bending moment in two main planes; (iii) shear force in two main planes; and (iv) torsional moment on the axis of the bar.

Two lines for representation of the deformation of the wings were chosen: (i) a line along the longitudinal axis (yellow arrow) and (ii) a line along a transverse axis near the end of the wing (red arrow), as can be seen in Fig. 5, Fig. 6, Table 2 and Table 3 as follows:

The longitudinal direction is divided into 20 equal parts to the two wings, whereas the transverse direction was divided into 10 parts.

It is observed that the relationship between the deformation of the posterior and anterior wings rotates around 2.4, e.g. the posterior wing support 2.4 times more load than the anterior wing. In fact, while the area of the posterior wing is $550 \mathrm{~mm}^{2}$, the area of the anterior wing is $410 \mathrm{~mm}^{2}$, e.g. 25 percenthigher. Furthermore, the stiffness of posterior exoskeleton is greater than the anterior; this also contributes to the increased absorption by the posterior wing load.

The graph of Fig. 7 shows the deformed shaped curves of two wings in longitudinal section (Fig. 5, Fig. 6 and Table 2).

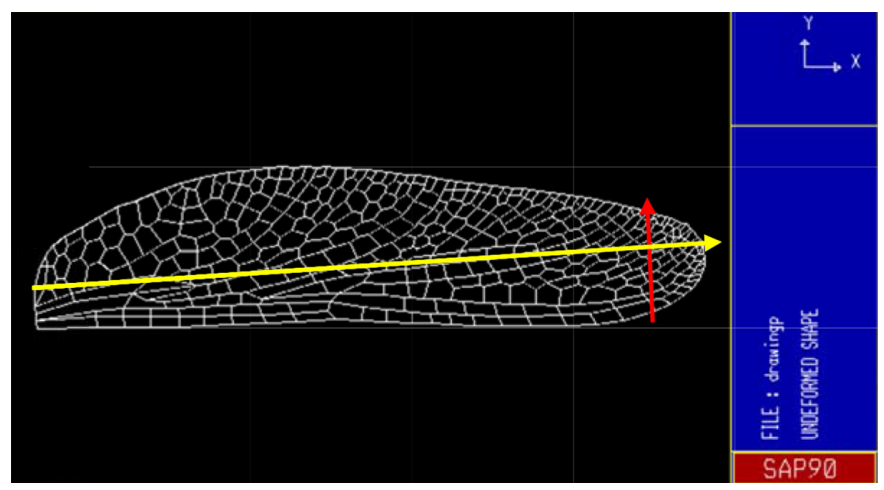

Figure 5: Anterior wing: (i) yellow arrow, (ii) red arrow.

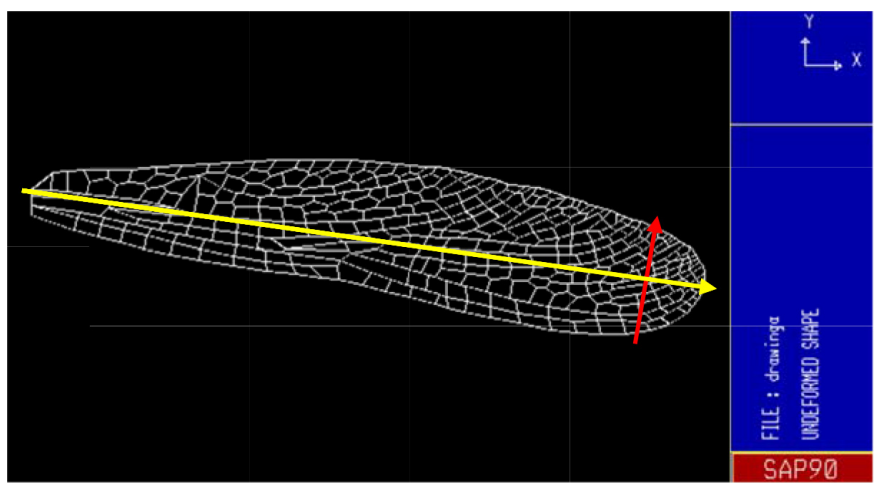

Figure 6: Posterior wing: (i) yellow arrow, (ii) red arrow. 
194 U. T. Bezerra \& N. P. Barbosa, Int. J. of Design \& Nature and Ecodynamics. Vol. 9, No. 3 (2014)

Table 2: Longitudinal and transversal directions: anterior and posterior wings.

\begin{tabular}{|c|c|c|c|c|c|c|c|}
\hline \multirow{2}{*}{$\frac{\text { Length }}{[\mathrm{mm}]}$} & \multicolumn{3}{|c|}{ Longitudinal [mm] } & \multirow{2}{*}{$\frac{\text { Width }}{[\mathrm{mm}]}$} & \multicolumn{3}{|c|}{ Transversal [mm] } \\
\hline & Ante. & Post. & Rel. & & Ante. & Post. & Rel. \\
\hline 0 & 0.00 & 0.00 & - & 0 & 2.64 & 6.64 & 2.52 \\
\hline 2 & 0.02 & 0.04 & 2.00 & 1 & 2.62 & 6.54 & 2.50 \\
\hline 4 & 0.07 & 0.14 & 2.00 & 2 & 2.75 & 6.63 & 2.41 \\
\hline 6 & 0.12 & 0.22 & 1.83 & 3 & 2.75 & 6.79 & 2.47 \\
\hline 8 & 0.21 & 0.52 & 2.48 & 4 & 2.74 & 6.83 & 2.49 \\
\hline 10 & 0.26 & 0.62 & 2.38 & 5 & 2.78 & 6.95 & 2.50 \\
\hline 12 & 0.40 & 0.99 & 2.48 & 6 & 2.77 & 6.91 & 2.49 \\
\hline 14 & 0.52 & 1.16 & 2.23 & 7 & 2.83 & 7.00 & 2.47 \\
\hline 16 & 0.73 & 1.76 & 2.41 & 8 & 2.82 & 7.04 & 2.50 \\
\hline 18 & 0.87 & 2.06 & 2.37 & 9 & 2.84 & 7.09 & 2.50 \\
\hline 20 & 1.04 & 2.46 & 2.37 & 10 & 2.88 & 7.10 & 2.47 \\
\hline 22 & 1.28 & 2.94 & 2.30 & & & & \\
\hline 24 & 1.37 & 3.49 & 2.55 & & & & \\
\hline 26 & 1.64 & 3.82 & 2.33 & & & & \\
\hline 28 & 1.86 & 4.54 & 2.44 & & & & \\
\hline 30 & 2.06 & 4.91 & 2.38 & & & & \\
\hline 32 & 2.35 & 5.36 & 2.28 & & & & \\
\hline 34 & 2.58 & 5.92 & 2.29 & & & & \\
\hline 36 & 2.72 & 6.52 & 2.40 & & & & \\
\hline 38 & 2.95 & 7.00 & 2.37 & & & & \\
\hline 40 & 3.21 & 7.46 & 2.32 & & & & \\
\hline
\end{tabular}

Table 3: Reactions.

\begin{tabular}{lcccc}
\hline Wing & Joint & Moment X [gf.mm] & Moment Y [gf.mm] & Shear Z [gf] \\
\hline A & 88 & -0.57 & -10.17 & -1.07 \\
A & 89 & -4.67 & -108.69 & 9.41 \\
A & 90 & -19.57 & -206.03 & 16.99 \\
A & 01 & -13.08 & -98.31 & 8.71 \\
P & 100 & 114.08 & -292.87 & 53.56 \\
P & 101 & 29.93 & -196.46 & -15.82 \\
P & 102 & 66.70 & -434.89 & 12.50 \\
P & 01 & 28.06 & -198.12 & -0.80 \\
\hline
\end{tabular}

In Fig. 7 one can see the higher deformation of the posterior wing and the parabolic shape $\left(\mathrm{R}^{2}=0.9970\right.$ and 0.9973$)$, typical of beams in balance.

The most significant efforts, of course, were obtained in the embedded parts (connection to the trunk of the animal). They are located in Fig. 8 and presented in Table 3. 


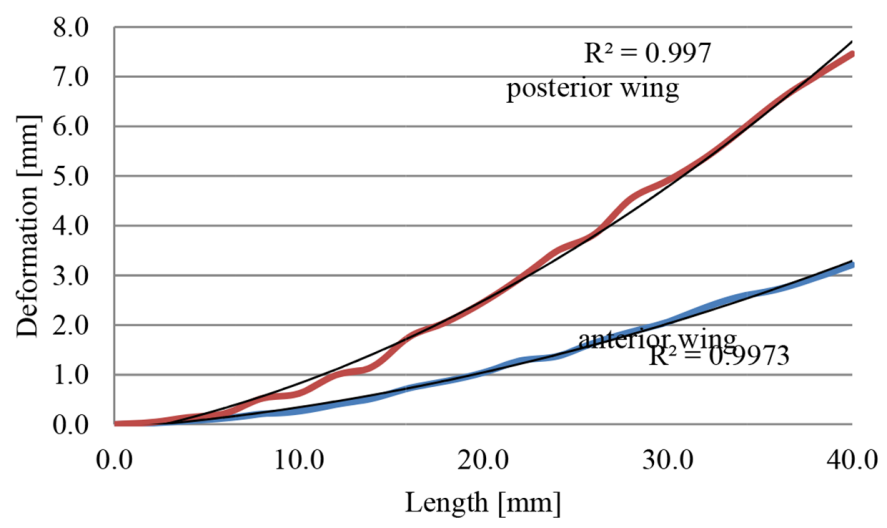

Figure 7: Longitudinal deformation of wings.

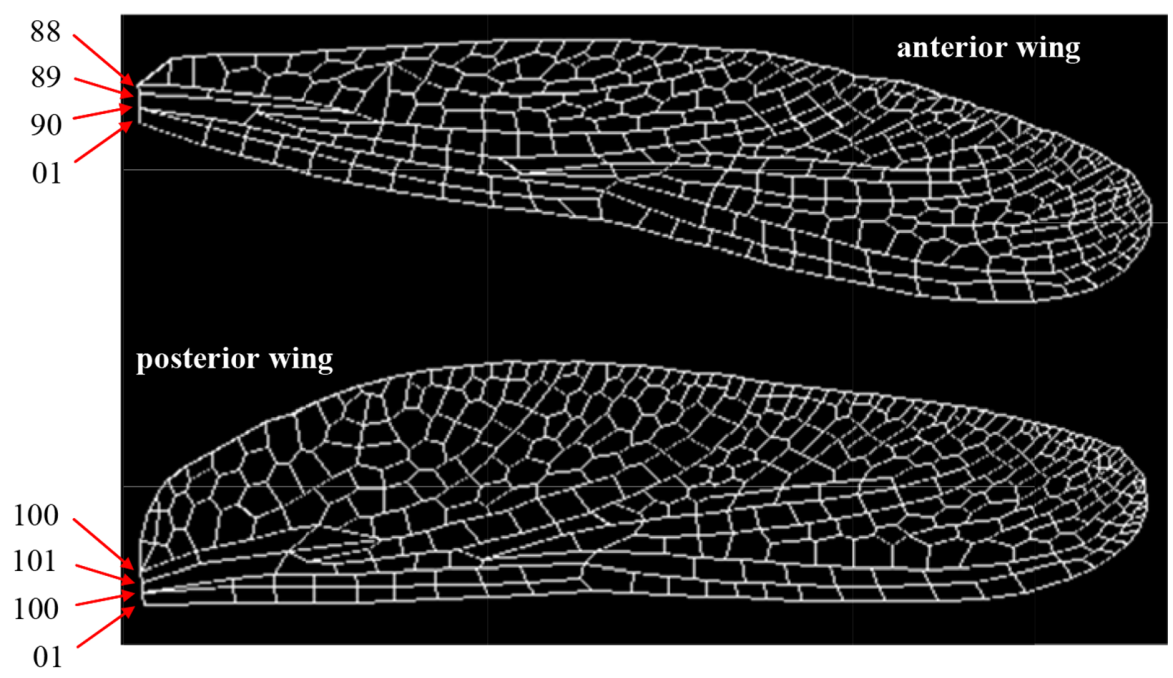

Figure 8: Location of support joints.

The joints 90 (anterior wing) and 102 (posterior wings) have double the bending moment of the side joints (89-01 and 101-01), respectively. In fact, in these joints run two beams of the same dimension, and it is in these regions that concentrate larger frames.

\section{CONCLUSIONS}

The relationship between the number of ramifications (frames) of the exoskeleton of dragonfly and their crosses (joints) closely resembles the golden number (1.618).

The deformation of the posterior wing is approximately 2.4 times larger than the anterior wing.

For further effort frames, nature provides larger cross sections.

There are four strong substructures in the posterior wing, whereas in the anterior wing this value is three. 
196 U. T. Bezerra \& N. P. Barbosa, Int. J. of Design \& Nature and Ecodynamics. Vol. 9, No. 3 (2014)

\section{ACKNOWLEDGEMENTS}

The authors are grateful to the Universe, since they received no incentive to participate in this enjoyable, nice, lovely, and so cool conference!

\section{REFERENCES}

[1] Heyman, J., Análisis de estructuras: un estudio histórico, 1st edn., Instituto Juan de Herrera: Madrid, 2004.

[2] Vasconcelos, A.C., Máquinas da natureza: um estudo da interface entre biologia e engenharia, 1st edn., IBRACON: São Paulo, 2004.

[3] Salvadori, M., Why buildings stand up? 1st edn., W. W. Norton Company and Inc.: New York, 2006.

[4] Barnes, R.D., Zoologia dos invertebrados, 7th edn., Roca: São Paulo, 2005.

[5] Wilson, E.L. \& Habibullah, A., SAP90: a series of computer programs for the static and dynamic finite element analysis of structures. User's Manual. Computers and Structures, Inc.: California, 1988.

[6] Devlin, K., Mathematics: the science of patterns, 1st edn., W. H. Freeman and Company: New York, 2002. 